\title{
Potensi Ekstrak Buah Mangrove Xylocarpus granatum Untuk Pemberantasan Larva Nyamuk Aedes aegypti
}

\section{Potentials of Mangrove Fruit Extract Xylocarpus granatum for Aedes aegypti Mosquito Repellent}

\author{
Delianis Pringgenies ${ }^{1 *}$, Rini Widiyadmi ${ }^{2}$, Ervia Yudiati ${ }^{1}$, \\ Muhammad Syaifudien Bahry ${ }^{1}$ dan Ali Djunaedi ${ }^{1}$
}

\author{
${ }^{1}$ Program Studi IImu Kelautan, Fakultas Perikanan dan IImu Kelautan, Universitas Diponegoro \\ Jl. Prof. H. Soedarto, S.H, Tembalang, Semarang, Jawa Tengah 50275 Indonesia \\ ${ }^{2}$ Sekolah Islam Al Azhar 14 \\ Jl. Klentengsari No. 1, Pedalangan, Semarang, Jawa Tengah 50275 Indonesia \\ *Email: pringgenies@undip.ac.id
}

\begin{abstract}
ABSTRAK
Tujuan penelitian adalah untuk mengetahui potensi ekstrak buah mangrove Xylocarpus granatum sebagai anti larva nyamuk Aedes aegypti. Uji larva nyamuk dengan memasukkan masing-masing 10 ekor larva nyamuk yang dimasukkan ke dalam 7 botol cup tranparan kecil, masing- masing untuk 50, 100, 250, 500, 1000 ppm sampel ektrak, kontrol negative dan kontrol positive. Hasil penelitian memperlihatkan bahwa pengaruh tingkat mortalitas larva nyamuk terhadap ekstrak buah mangrove Xylocarpus granatum pada jam 1 memperlihatkan bahwa pada konsentrasi 1000 ppm, persentasi mortalitas nyamuk tertinggi adalah 81,34 \%, dan pada konstrasi ekstrak buah mangrove Xylocarpus granatum $100 \mathrm{ppm}$ terendah mortalitasnya $=68,8 \%$. Perlakuan pada jam 3 memperlihatkan bahwa pada konsentrasi ekstrak buah mangrove $500 \mathrm{ppm}$ tingkat mortalitas larva nyamuk tertinggi (80\%). Pada konsentrasi ekstrasi buah mangrove 250 ppm, mortalitasnya 66,70\% dan konsentrasi ekstral buah mangrove pada 100 ppm, mortalitasnya adalah $40 \%$. Hasil peneltian pada jam ke 24 memperlihatkan bahwa pada konsentrasi ekstrak buah mangrove mencapai 1000 pmm, mortalitasnya $100 \%$, pengamatan jam ke 48 mortalitasnya $100 \%$. Sedang pada perlakuan control positif, keluulushidupan larva nyamuk adalah $0 \%$ dan pada control negative, kelulushidupan larva nyamuk adalah $100 \%$. Kesimpulan: bahwa ekstrak buah mangrove Xylocarpus granatum berpotensi sebagai anti larva nyamuk pada konsentrasi 1000 ppm.
\end{abstract}

Kata kunci : mangrove, Xylocarpus granatum, anti nyamuk, Aedes aegypti

\begin{abstract}
It was assumed that mangrove fruits has some insecticidal biosubstances. Aim of the research is the potentials of mangrove Xylocarpus granatum fruit extract as the anti mosquito (Aedes aegypti) repellent. Experiment using of 10 mosquito larvae in 7 bottles each filled with $50 ; 100 ; 250 ; 500$ and $1000 \mathrm{ppm}$ fruit extract, negative and positive control. The experiment reveals that after 1 hour treatment, the $1000 \mathrm{ppm}$ exctract had the hihgest mosquito larvae mortality of $81.34 \%$, while the lowest extract of 100 $\mathrm{ppm}$ had $68.8 \%$ mortality. After 3 hours of extract treatment the $500 \mathrm{ppm}$ had the hihgest mortality of $80 \%, 250 \mathrm{ppm}$ with $66.70 \%$ and $100 \mathrm{ppm}$ with $40 \%$ mortality. Result of experiment after 24 as well as 48 hours treatment the $1000 \mathrm{ppm}$ extract had $100 \%$ mortality. In the positive control had $0 \%$ mortality and the negative control had $100 \%$ of survival. The summary is that the mangrove Xylocarpus granatum fruit extract had a potential as mosquito repellent at $1000 \mathrm{ppm}$ fruit extract.
\end{abstract}

Keywords : Xylocarpus granatum, mosquito repellent, Aedes aegypti

\section{PENDAHULUAN}

Mangrove merupakan tanaman yang tumbuh di daerah pasang - surut dan komunitasnya sering disebut hutan mangrove atau hutan bakau. Menurut DepHut (2003), hutan mangrove juga salah satu lahan basah yang paling produktif, karena tumbuh di daerah pasang surut pantai, hutan mangrove diketahui memiliki potensi kekayaan hayati yang disebut dengan komunitas mangrove. Komunitas mangrove terdiri dari tumbuhan, hewan dan mikrobia, namun tanpa kehadiran tumbuhan mangrove, kawasan tersebut tidak dapat disebut ekosistem mangrove (Jayatissa et al., 2002. Ekosistem mangrove adalah 
suatu system yang terdiri atas berbagai tumbuhan, hewan dan mikrobia yang berinteraksi dengan lingkungan di habitat mangrove (SNM, 2003).

Indonesia adalah salah satu negara yang memiliki hutan mangrove terbesar dengan luas ekosistem mangrove sekitar $27 \%$ dari luas mangrove di dunia, serta memiliki ekosistem mangrove dan keragaman jenis tertinggi di dunia yang tersebar di wilayah pesisir Sumatera, Kalimantan, dan Papua. (Wijayanti, 2007). Dari 70 jenis mangrove yang ditemukan di dunia, sebagian besar dapat dijumpai di wilayah Indonesia (Kitamura et al., 1997).

Mangrove Xylocarpus banyak ditemukan di perairan Karimunjawa, buahnya berbentuk seperti buah kelapa dan rasanya sangat pahit. Jenis pohon mangrove ini ada dua yaitu, $X$. granatum dan $X$. molucoensis yang berupa pohon berukuran sedang. Mangrove Xylocarpus mempunyai biji yang mengeluarkan minyak, bermanfaat untuk obat-obatan diare disenteri dan luka terbakar serta berkhasiat sebagai tonikum. Seduhan buah segar dan kulit pohon ini dapat membantu menahan rasa sakit karena kelaparan dan sakit mag. Gondok yang membengkak pada muka dapat disembuhkan dengan biji pohon ini. Kulit kayu pohon ini yang rasanya pahit mengandung alkaloid yang berkhasiat sebagai obat malaria dan juga dapat menghasilkan tannin (Sukardjo, 1984). Selanjurnya Nurdiana R (2012) mengatakan bahwa mangrove jenis Xylocarpus telah banyak digunakan sebagai insektisida nabati.

Berdasarkan hal tersebut, maka tujuan peneltian adalah untuk mengetahui potensi ekstrak buah mangrove Xylocarpus granatum sebagai anti larva nyamuk, tingkat Mortalitas larva nyamuk Aedes aegypti setelah diberi ekstrak mangrove Xylocarpus pada konsentrasi yang berbeda dan waktu optimum untuk membunuh larva nyamuk Aedes aegypti.

\section{METODE PENELITIAN}

Bahan yang digunakan dalam penelitian ini adalah buah tanaman mangrove (Xylocarpus granatum) yang dikumpulkan dari perairan Semarang. Proses persiapan penelitian meliputi: pengeringan sampel daun Nimba yang dikeringkan dibawah sinar matahari secara tidak langsung selama $4-7$ hari dan dilanjutkan dengan pembuatan tepung Nimba. Sebanyak $500 \mathrm{~g}$ serbuk daun mimba Azadirachta indica A. Juss diekstraksi dengan cara maserasi dengan menggunakan
$5 \mathrm{~L}$ metanol teknis sampai semua komponen habis terekstraksi. Ekstrak metanol yang diperoleh diuapkan dengan penguap putar vakum sampai pelarut habis kemudian di partisi dengan menggunakan separatory funnel. Partisi dari etil asetat diuapkan kembali sampai semua solven habis menguap. Masing-masing ekstrak yang diperoleh yaitu ektrak daun mimba diuji aktivitas biologisnya terhadap larva nyamuk Aedes aegypti, selanjutnya uji toksisitas terhadap larva nyamuk Aedes aegypti.

Media larva pertumbuhan larva nyamuk Aedes aegypti dibuat meletakkan telur dari larva nyamuk Aedes aegypti kedalam air aquades di dalam nampan. Media pertumbuhan disimpan pada tempat yang lembab sampai telur dari larva nyamuk tersebut menetas dan siap digunakan dalam pengujian yakni pada fase instar 4 . Botol cup tranparan kecil disiapkan untuk pengujian, yakni masing-masing untuk 50; 100; 250; 500; 1000 ppm; kontrol negative; kontrol positive dengan masing masing 2 kali ulangan. Setip botol di berikan ektrak yang telah dilarutkan dengan DMSO sesuai konsentrasi ujinya kemuian di tambahkan dengan aquades hingga volumenya $10 \mathrm{ml}$. Sepuluh ekor larva ditambahkan pada setiap botol kemudian dilakukan pengamatan uji toksisitas terhadap larva nyamuk Aedes aegypti. Kontrol positive menggunakan larutan abate sesui WHO $100 \mathrm{ppm} / 10 \mathrm{ml}$ sedangkan kontrol negatif adalah akuadest. Pengamatan dilakukan setelah $1,3,18,20$, 24, 48 jam terhadap kematian larva nyamuk.

\section{HASIL DAN PEMBAHASAN}

Hasil penelitian tentang pengaruh tingkat mortalitas larva nyamuk terhadap ekstrak buah mangrove Xylocarpus granatum pada jam 1 memperlihatkan bahwa pada konsentrasi ekstrak buah mangrove Xylocarpus granatum 50 ppm, larva nyamuk semuanya mati. Kemudian pada konsentrasi $1000 \mathrm{ppm}$, persentasi mortalitas nyamuk tertinggi adalah $81,34 \%$, dan pada konstrasi ekstrak buah mangrove Xylocarpus granatum $100 \mathrm{ppm}$ terendah mortalitasnya $=68,8 \%$ seperti yang tertera pada Gambar 1.

Selanjutnya perlakuan tentang pengaruh tingkat mortalitas larva nyamuk terhadap ekstrak buah mangrove Xylocarpus granatum pada jam 3 memperlihatkan bahwa pada konsentrasi ekstrak buah mangrove 500 ppm tingkat mortalitas larva nyamuk tertinggi $(80 \%)$, sehingga terlihat kelulus hidupan larva nyamuk $20 \%$. Selanjutnya pada konsentrasi ekstrak buah mangrobe 
1000 ppm, mortalitasnya mencapai 73\% dan kelulus hidupan larv nyamuk mencapai $23 \%$. Pada konsentrasi ekstrasi buah mangrove 250 ppm, mortalitasnya 66,70\% dan kelulus hidupannya adalah 33,3\%. Selanjutnya konsentrasi ekstral buah mangrove pada 100 ppm, mortalitasnya adalah 40\%, kelulushidupannya 60\%. Sedangkan untuk konsentrasi ekstrak buah mangrove 50 ppm, larva nyamuk tidak ada yang mati. $100 \%$ masih hidup seperti pada awal perlakuan.

Hasil penelitian pada jam ke 18 ekstrak buah mangrove terhadap larva nyamuk Aedes aegypti memperlihatkan hasil yag tidak jauh berbeda dibandingkan denganjam ke 3 pada 1000 ppm, 500 ppm dan 250 ppm. Persentase kelulushidupan larva nyamuk ekstrak buah mangrove masing masing pada konsentrasi yang berbeda adalah sebabagi berikut: 1000 ppm adalah $20 \%$ (mortalitas larva nyamuk mencapai 80\%), 500 ppm adalah $23 \%$ (mortalitas larva nyamuk mencapai 67\%), 250 ppm adalah 43\% (mortalitas larva nyamuk mencapai 807\%),
100 ppm adalah 70\% (mortalitas larva nyamuk mencapai 30\%), dan 50 ppm adalah $60 \%$ (mortalitas larva nyamuk mencapai $40 \%$ ) seperti yang terlihat pada Gambar 3.

Hasil penelitian tentang pengaruh ekstrak buah mangrove terhadap kelulushidupan larva nyamuk pada jam ke 20 memperlihatkan bahwa pada konsentrasi ekstrak buah mangrove masing-masing: 1000 ppm, kelulushidupan larve nyamuk sudah mencapai sangat rendah, yaitu 10\% (mortalitas 90\%), sedang 500 ppm adalah 16\% (mortalitas 84\%), 250 ppm adalah 40\% (mortalitas 60\%), 100 ppm adalah 56\% (mortalitas 44\%) dan 50 ppm adalah 56\% (mortalitas 44\%). Sedang untuk kontrol positif, kelulushidupannya larva nyamuk mencapai $0 \%$ dan untuk control negative, kelulushidupannya mencapai $100 \%$ seperti yang terlihat pada Gambar 4.

Hasil peneltian pada jam ke 24 tentang pengaruh konsentrasi ekstrak buah mangrove terhadap keluus hidupan larva nyamuk sudah memperlihatkan hasil yang nyata.

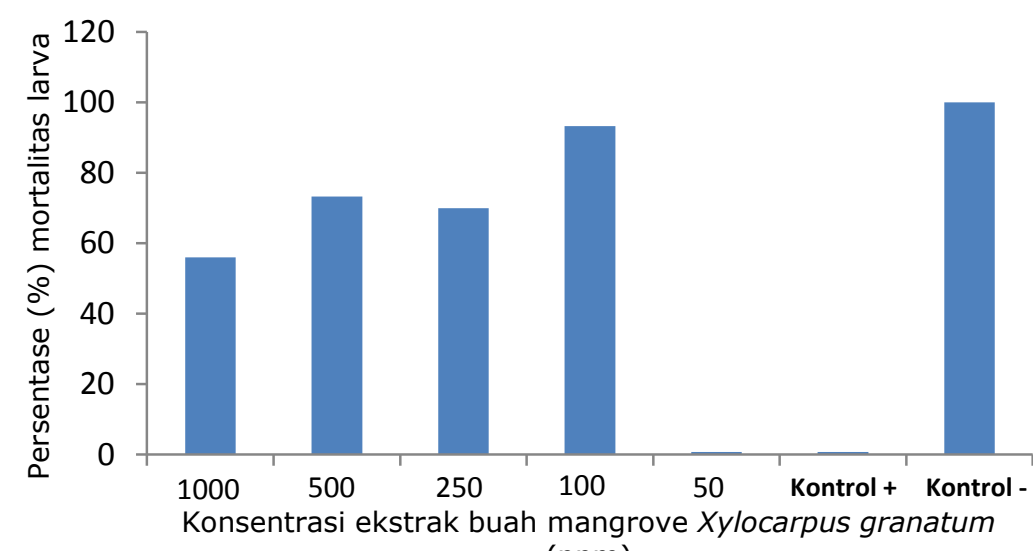

(ppm)

Gambar 1. Kelulushidupan (\%) ekstrak buah mangrove mangrove Xylocarpus granatum dengan konsentrasi (ppm) yang berbeda terhadap Larva nyamuk dalam waktu jam 1

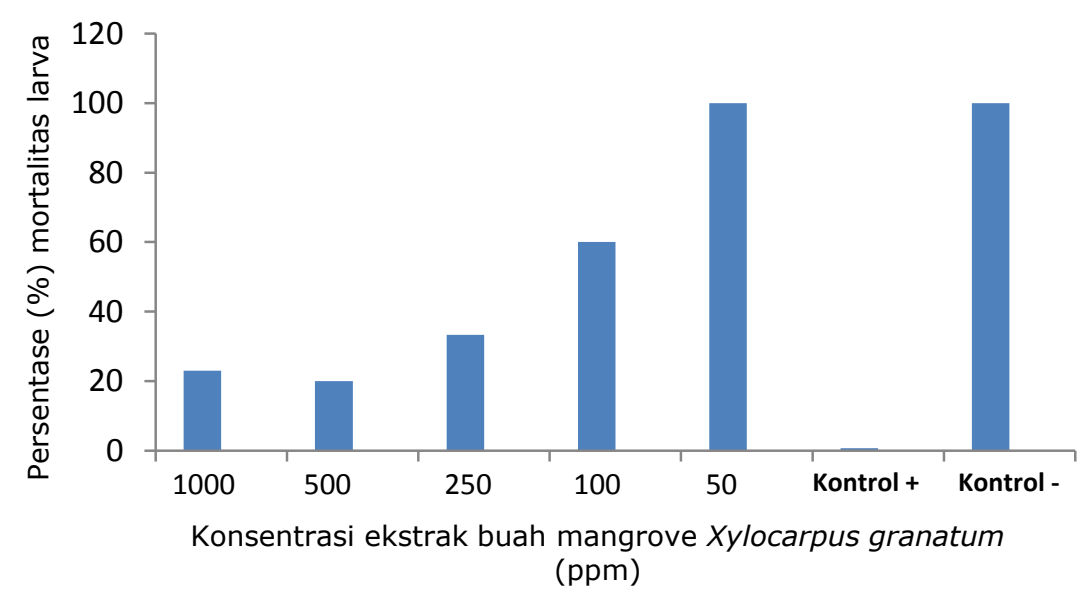

Gambar 2. Kelulushidupan (\%) ekstrak buah mangrove mangrove Xylocarpus granatum dengan konsentrasi (ppm) yang berbeda terhadap Larva nyamuk dalam waktu jam 3 
Konsentrasi ekstrak buah mangrove mencapai 1000 ppm, kelulushidupan larva nyamuk sudah $0 \%$, artinya semua larva mati (mortalitas $1000 \%$ ), sedang konsentrasi ekstrak buah mangrove 500 ppm, kelulushidupan larva nyamuk adalah $16 \%$ (mortalitas 84\%), konsentrasi ekstrak buah mangrove $250 \%$, kelulushidupan larva nyamuk $43 \%$ (mortalitasnya $57 \%$ ), pada 100 ppm kelulushidupannya adalah $40 \%$ (mortalitas 60\%) dan pada konsentrasi ekstrak uah mangrove 50 ppm, kelulushidupan larva nyamuk mencapai 53\% (mortalitas 47\%). Seperti yang terlihat pada Gambar 5.

Selanjutnya hasil pengamatan jam ke 48 tentang pengaruh konsentrasi yang berbeda ekstrak buah mangrove terhadap kelulushidupan larva nyamuk menghasilkan: kosentrasi 1000 ppm, kelulushidupan larva nyamuk adalah 0\% (mortalitas 100\%); konsentrasi 500 ppm kelulushidupan larva nyamuk 33\% (mortalitas 67\%); konsentrasi 250 ppm kelulushidupan larva nyamuk 16,6 $\%$ (mortalitas $83,4 \% \%$ ); konsentrasi 100 ppm kelulushidupan larva nyamuk $20 \%$ (mortalitas 80\%); konsentrasi 50 ppm kelulushidupan larva nyamuk 46,6\% (mortalitas 53,4\%). Sedang pada perlakuan control positif, keluulushidupan larva nyamuk adalah $0 \%$ dan pada control negative, kelulushidupan larva nyamuk adalah $100 \%$ seperti yang terlihat pada Gambar 6 .

Hasil penelitian memperlihatkan bahwa semakin tinggi konsentrasi ekstrak buah mangrove Xylocarpus granatum yang dilakukan kepada larva nyamuk Aedes aegypti, maka semakin renah kelulushidupannya, artinya mortalitasya semakin tinggi. Hasil penelitian

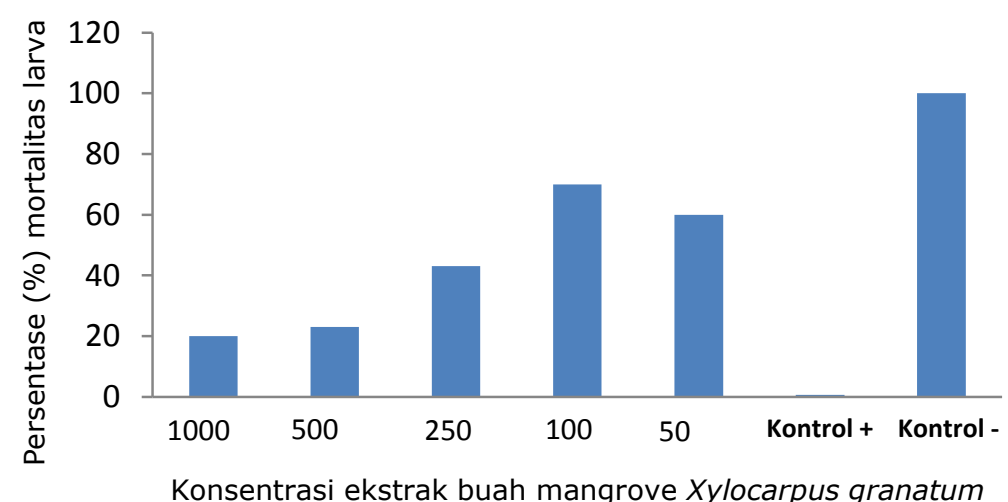

(ppm)

Gambar 3. Kelulushidupan (\%) ekstrak buah mangrove mangrove Xylocarpus granatum dengan konsentrasi (ppm) yang berbeda terhadap Larva nyamuk dalam waktu jam 18

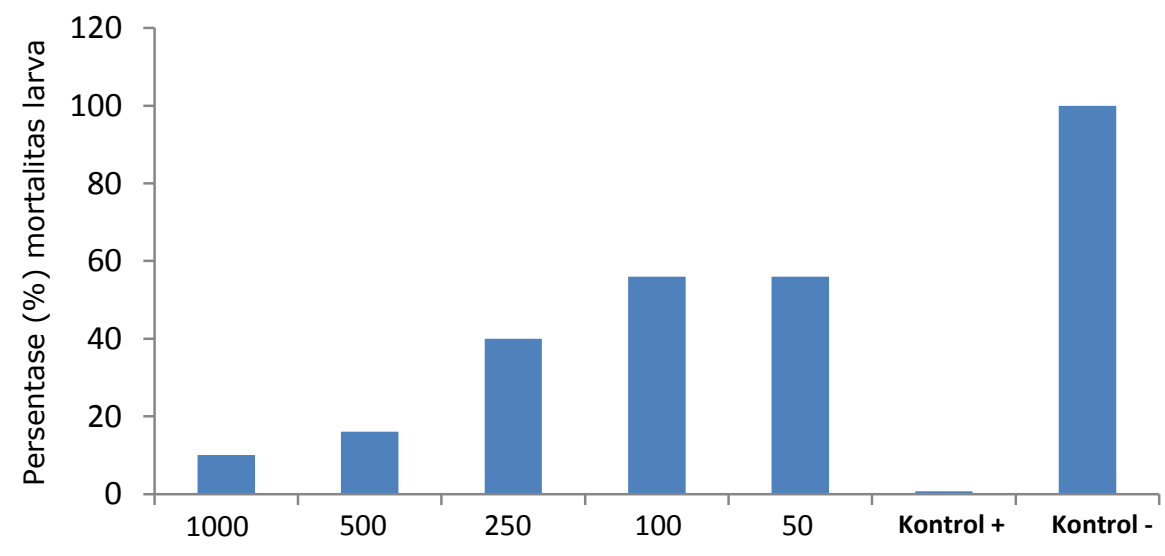

Konsentrasi ekstrak buah mangrove Xylocarpus granatum (ppm)

Gambar 4. Kelulushidupan (\%) ekstrak buah mangrove mangrove Xylocarpus granatum dengan konsentrasi (ppm) yang berbeda terhadap Larva nyamuk dalam waktu jam 20 


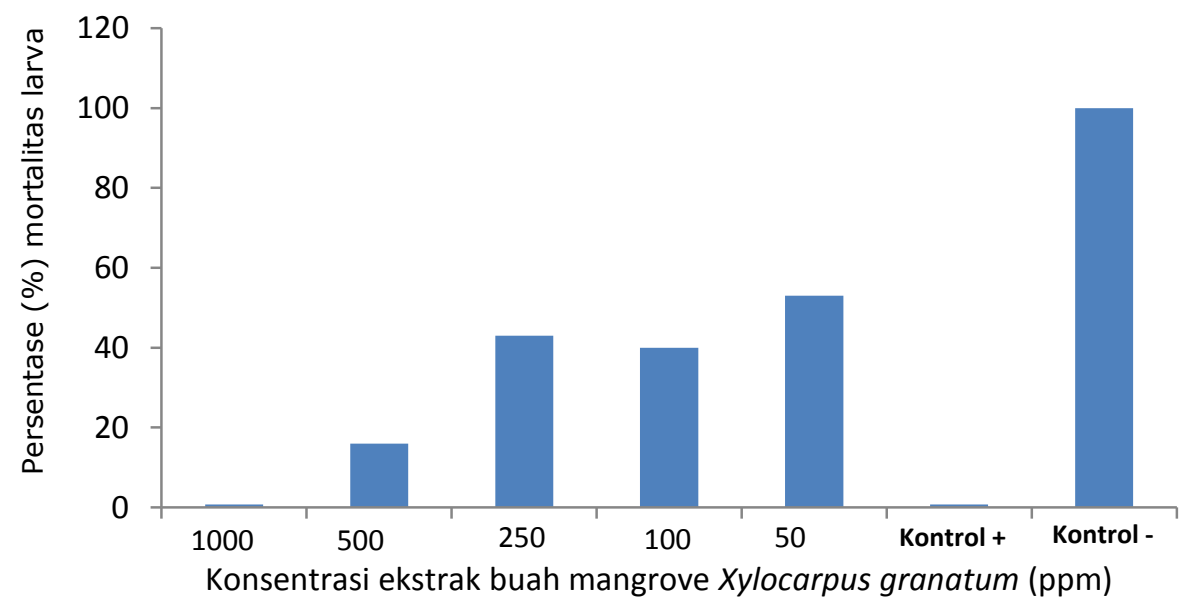

Gambar 5. Kelulushidupan (\%) ekstrak buah mangrove mangrove Xylocarpus granatum dengan konsentrasi (ppm) yang berbeda terhadap Larva nyamuk dalam waktu jam 24

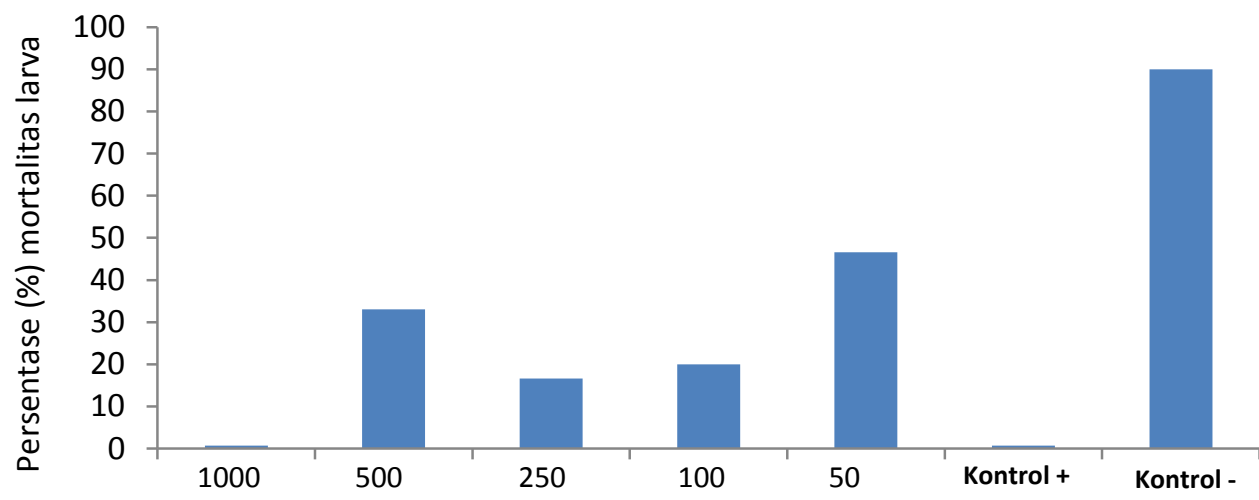

Konsentrasi ekstrak buah mangrove Xylocarpus granatum (ppm)

Gambar 6. Kelulushidupan (\%) ekstrak buah mangrove mangrove Xylocarpus granatum dengan konsentrasi (ppm) yang berbeda terhadap Larva nyamuk dalam waktu jam 48

membuktukan bahwa dengan konsentrasi 1000 ppm ekstrak mangrove dapat mematikan seluruh larva nyamuk. Hasil penelitian ekstrak mangrove dengan konsentrai 1000 ppm dapat meningkatkan mortalitas hingga mencapai $100 \%$ merupakan hasil yang sangat menarik dan ekstrak mangrove sangat potensi untuk membunuh larva nyamuk dibandingkan dengan ekstrak daun sereh dan daun sirsak. Kolo et al. (2018) mengatakan bahwa daun sereh dan daun sirsak dapat membunuh larva nyamuk Aedes aegypti pada konsentrasi 2000 ppm. Berbeda dengan ekstrak daun Oleander. Tanaman Oleander $N$. oleander banyak dijumpai di Sulawesi Tengah sebagai tanaman hias di pekarangan rumah maupun di pinggir jalan. Tanaman tersebut berpotensi sebagai larvasida nabati karena bersifat toksik. Menurut Isnawati. R, Murni, Nelfita (2015) bahwa N. oleander banyak mengandung senyawa beracun, yang paling tinggi kandungannya adalah oleandrin dan nerin 8 sebagai glikosida jantung Tanaman $N$. oleander ditemukan lebih efektif memberantas larva nyamuk $C x$. quinquefasciatus dari pada nyamuk Aedes aegypti. Sedang nyamuk Aedes aegypti berpotensi penyebab timbulnya penyakit demam berdarah.

Nyamuk, banyak ditemukan di daerah yang kumuh dan t habitat nyamuk adalah di wilayah yang gersang dan tidak ada tanaman. Seperti yang dikatakan oleh Setiyaningsih et al., (2015) bahwa populasi tertinggi nyamuk ditemukan pada ekosistem non hutan jauh pemukiman dengan kepadatan per jam (man hour density $=$ MHD) adalah 4,42 ekor/orang/jam. Tempat perkembangbiakan Anopheles ludlowae banyak ditemukan di kobakan-kobakan sepanjang sungai. Tetapi pada ekosistem tanaman, populasi nyamuk tidak setinggi di area tersebut. Hal tersebut disebabkan karena hamper semua ekstrak tanaman berpotensi menghalau nyamuk dari 
lingkungannya. Bagavan, A Abdul Rahuman (2011) mengatakan bahwa senyawa aktif yang terkandung dalam ekstrak tanaman, berpotensi untuk pengendalian vector penyakit. Selanjutnya dikatakan oleh Noshirma dan Willa RW (2016) bahwa banyak tanaman yang mengandung minyak atsiri, saponin dan flavonoid dan efektif sebagai larvasida.

\section{KESIMPULAN}

Hasil penelitian disimpulkan bahwa ekstrak mangrove Xylocarpus granatum berpotensi membunuh larva nyamuk Aedes aegypti. Pada konsentrasi 1000 ppm ekstrak mangrove Xylocarpus granatum dapat membunuh semua nyamuk Aedes aegypti.

\section{UCAPAN TERIMA KASIH}

Ucapan terima kasih ditujukan kepada Ibu Ekawati Justiar (Ibu Bupati Bangka Selatan) dan bapak H. Haris Setiawan, MT (Kepala Dinas Pariwisata, Kepemudaan dan Olahraga Bangka Selatan) yang telah mengirim buah mangrove Xylocarpus granatum. Ucapan terima kasih juga ditujukan kepada Sekolah Islam Al Azhar 14, Semarang yang telah mendukung fasilitas dalam penelitian.

\section{REFERENSI}

Bagavan, A Abdul Rahuman. 2011. Evaluation of larvicidal activity of medicinal plant extracts against three mosquito vectors. Asian Pacific J. Trop. Med. pp 29-34.

Departemen Kehutanan. 2003. Surat Keputusan Menteri Kehutanan No. 305/Kpts-II/2003. Jakarta: Dephut.

Isnawati. R, Murni \& Nelfita. 2015. Uji Daya Bunuh Ekstrak Daun Nerium oleander $L$. Terhadap Larva Nyamuk Aedes aegypti dan Culex quinquefasciatus. J. Vektor Penyakit, 9(2):59-64

Jayatissa, L.P., Dahdouh-Guebas, F. \& Koedam, N. 2002. A review of the floral composition and distribution of mangroves in Sri Lanka. Botani. J. Linn. Soc. 138:29-43.

Kitamura, S., Anwar, C., Chaniago, A. \& Baba, S. 1997. Handbook of Mangroves in Indonesia; Bali \& Lombok. Denpasar: The Development of Sustainable Mangrove Management Project, Ministry of Forest
Kolo, S.M.D., Fallob, G. \& Nenoc, S.D.R. 2018. Aktivitas Biolarvasida Ekstrak Daun Sirsak dan Serai Wangi Terhadap Larva Nyamuk Aedes aegypti. J. Saintek Lahan Kering. 1(1):13-16

Nurdiana R. 2012. Pemanfaatan Ekstrak Kloroform Kulit Batang Tumbuhan Nyiri Batu (Xylocarpus moluccensis (Lamk) M. Roem.) (Meliaceae) Sebagai Bioinsektisidan (Utilization Chloroform Extract of Plant Nyiri Batu Bark Xylocarpus moluccensis (Lamk) M. Roem.) (Meliaceae) for B. Unesa $J$. Chem. 1(2):66-68

Noshirma, M. \& Willa, R.W. 2016. Larvasida Hayati Yang Digunakan Dalam Upaya Pengendalian Vektor Penyakit Demam berdarah di Indonesia. Sel Jurnal Penelitian Kesehatan. 3(1):31-40

Sukristijono,. 1984. Ekosistem Mangrove. Oseana. Volume IX, Nomor 4:102-115,

Strategi Nasional Mangrove. 2003. Strategi Nasional Pengelolaan Mangrove di Indonesia (Draft Revisi); Buku II: Mangrove di Indonesia. Jakarta: Kantor Menteri Negara Lingkungan Hidup.

Sukardjo, S. 1984. Ekosistem mangrove. Oseana. IX(4):102-115

Setiyaningsih, R., Alfiah, S., Garjito, T.W.A., Heriyanto, B. 2015. Assesment penyakit tular vektormalaria di Kabupaten Banyumas. Media Litbang Kesehat. 25(2):1-6.

Wijayanti, E. D., Poernomo, B., \& Utomo, B. 2008. Pengaruh pemberian ekstrak daun api-api (Avicenna marina) terhadap resorpsi embrio, berat badan dan panjang badan janin mencit. Veterinaria Medika. 1(1):9-12. 